DOI: $10.14451 / 1.192 .144$

\title{
ПРОСТРАНСТВЕННЫЙ АНАЛИЗ РОССИЙСКИХ ЦЕНТРОВ УНИВЕРСИТЕТСКОГО ПРЕВОСХОДСТВА И РАСЧЕТ РЕГИОНАЛЬНОЙ УНИВЕРСИТЕТСКОЙ КОНКУРЕНТОСПОСОБНОСТИ
}

\author{
(c) 2020 Московкин Владимир Михайлович \\ доктор географических наук
}

директор Центра развития публикационной активности, профессор кафедры мировой экономики Белгородский государственный национальный исследовательский университет, Россия, Белгород

E-mail: moskovkin@bsu.edu.ru

ORCID: 0000-0001-5587-4133

SPIN-код: 2719-8360

\section{(c) 2020 Чжан Хэ}

аспирант кафедры прикладной экономики и экономической безопасности

Белгородский государственный национальный исследовательский университет, Россия, Белгород E-mail: 1098006@bsu.edu.ru

ORCID: 0000-0001-8654-0697

\section{(c) 2020 ЛюЯвэй}

аспирант кафедры прикладной экономики и экономической безопасности Белгородский государственный национальный исследовательский университет, Россия, Белгород E-mail: angellywei@163.com

ORCID: 0000-0002-7939-7041

\section{Введение}

С момента запуска проекта «5-100» возник большой интерес к мониторингу позиционирования ведущих российских университетов в трех мировых рейтингах QS, THE и ARWU. По нашим экспериментам в расширенном поиске GoogleScholar в строке «точное словосочетание» кластеры публикаций, порожденные недавно веденными терминами «проект 5-100» и «project 5-100» насчитывают около 500 и 100 статей, соответственно. При этом отметим, что фактическое число откликов было выражено, соответственно, пятизначными и шестизначными цифрами, и поэтому потребовалась внимательная экспертная оценка достаточно большого числа откликов, чтобы прийти к реальным цифрам.

К сожалению, за исключением работы [1], в этих кластерах публикаций отсутствовали обобщающие работы, в которых была бы исследована динамика позиционирования всех ведущих российских университетов в рассматриваемых трех рейтингах за достаточно продолжительный период времени. В работе [1] такая динамика приведена и проанализирована за период с 2012 по 2017 год включительно для 52 российских университетов, которые хотя бы один раз вошли в один из рейтингов QS, THE и ARWU на этом интервале времени.

Зная распределение ведущих российских университетов в этих рейтингах за последние годы, можно распределить их по регионам, агрегировать их ранги (позиции в рейтингах) и прийти к понятию региональной университетской конкурентоспособности на глобальном уровне, так как мы рассматриваем столичные и региональные университеты в глобальных рейтингах. Такая методология для университетов ЦФО РФ, на примере рейтингов Webometrics, Эксперт РА и Интерфакс, была предложена в работе [2], которую мы применим и для университетов России, входящих в три ведущих мировых университетских рейтингов.

Регионы, в которых находятся университеты, входящие, по крайней мере, в один из трех рейтингов QS. THE, ARWU, мы назовем центрами университетского превосходства, а степень этого превосходства будем определять через расчет усредненного позиционирования университетов в этих рейтингах за весь рассматриваемый период времени с учетом числа университетов в регионе. Эти центры университетского превосходства, естественно, являются потенциальными полюсами инновационного роста соответствующих регионов. Они станут реальными полюсами, если удастся в регионах создать реальные инновационные кластеры на базе университетов, входящих в глобальные рейтинги, при тесном их взаимодействии с региональны- 
ми университетами, местной промышленностью и региональной властью.

\section{Материалы и методы исследования}

С целью пространственного анализа, мы будем выделять центры университетского превосходства по рейтингам QS и THE, так как в рейтинг ARWU входят всего четыре российских университета [1]. Рассматривая вхождения ведущих российских университетов в первые два рейтинга за последние три года, мы выделили 20 центров университетского превосходства, они же и регионы России (табл.1). Университетскую конкурентоспособность этих центров или регионов можно определить с помощью вектора $\left(n_{i}, R_{i}\right)$, где $n_{i}-$ количество университетов в $i$-ом регионе, $R_{i}-$ усредненный ранг университетов, входящих в $i$-ый регион [2].

Таблица 1. Распределение ведущих российских университетов по рейтингам QS и THE за последние три года

\begin{tabular}{|c|c|c|c|c|c|c|c|c|c|}
\hline \multirow[b]{2}{*}{ № } & \multirow[b]{2}{*}{ Регион } & \multirow[b]{2}{*}{ Город } & \multirow[b]{2}{*}{ Название университета } & \multicolumn{3}{|c|}{ QS } & \multicolumn{3}{|c|}{ THE } \\
\hline & & & & $\begin{array}{c}2018 \\
(2018- \\
2019)\end{array}$ & $\begin{array}{c}2019 \\
(2019- \\
2020)\end{array}$ & $\begin{array}{c}2020 \\
(2020- \\
2021)\end{array}$ & $\begin{array}{c}2018 \\
(2018- \\
2019)\end{array}$ & $\begin{array}{c}2019 \\
(2019- \\
2020)\end{array}$ & $\begin{array}{c}2020 \\
(2020- \\
2021)\end{array}$ \\
\hline \multirow{17}{*}{1} & \multirow{17}{*}{ г. Москва } & г. Москва & $\begin{array}{l}\text { Национальный исследовательский } \\
\text { университет «Высшая школа экономи- } \\
\text { ки» } 1,3\end{array}$ & 343 & 322 & 298 & $\begin{array}{c}301- \\
350\end{array}$ & $\begin{array}{c}251- \\
300\end{array}$ & $\begin{array}{c}251- \\
300\end{array}$ \\
\hline & & г. Москва & $\begin{array}{l}\text { Московский физико-технический } \\
\text { институт (государственный универси- } \\
\text { тет) } 1,3\end{array}$ & 312 & 302 & 281 & $\begin{array}{c}251- \\
300\end{array}$ & $\begin{array}{c}201- \\
250\end{array}$ & $\begin{array}{l}201- \\
250\end{array}$ \\
\hline & & г. Москва & $\begin{array}{l}\text { Первый Московский государственный } \\
\text { медицинский университет имени } \\
\text { И.М.Сеченова } 1\end{array}$ & & & & $1001+$ & $1001+$ & $1001+$ \\
\hline & & г. Москва & $\begin{array}{l}\text { Российский университет дружбы } \\
\text { народов } 1\end{array}$ & 446 & 392 & 326 & $\begin{array}{c}601- \\
800\end{array}$ & $\begin{array}{l}800- \\
1000\end{array}$ & $\begin{array}{l}800- \\
1000\end{array}$ \\
\hline & & г. Москва & $\begin{array}{l}\text { Национальный исследовательский } \\
\text { технологический университет «МИ- } \\
\text { СиС» } 1,3\end{array}$ & 476 & 451 & 428 & & $\begin{array}{c}601- \\
800\end{array}$ & $\begin{array}{c}601- \\
800\end{array}$ \\
\hline & & г. Москва & $\begin{array}{l}\text { Национальный исследовательский } \\
\text { ядерный университет «МИФИ» 1,3 }\end{array}$ & 329 & 329 & 314 & $\begin{array}{c}351- \\
400\end{array}$ & $\begin{array}{c}401- \\
500\end{array}$ & $\begin{array}{c}401- \\
500\end{array}$ \\
\hline & & г. Москва & $\begin{array}{l}\text { Российский национальный исследо- } \\
\text { вательский медицинский университет } \\
\text { имени Н.И. Пирогова } 3\end{array}$ & & & & $1001+$ & $1001+$ & $1001+$ \\
\hline & & г. Москва & $\begin{array}{l}\text { Московский авиационный институт } \\
\text { (национальный исследовательский } \\
\text { университет) } 3\end{array}$ & & & & $1001+$ & $1001+$ & $1001+$ \\
\hline & & г. Москва & $\begin{array}{l}\text { Национальный исследовательский } \\
\text { университет «МИЭТ» } 3\end{array}$ & & & & $1001+$ & $1001+$ & $1001+$ \\
\hline & & г. Москва & $\begin{array}{l}\text { Российский государственный универ- } \\
\text { ситет нефти и газа (национальный ис- } \\
\text { следовательский университет) имени } \\
\text { И.М.Губкина } 3\end{array}$ & & & & & $1001+$ & $1001+$ \\
\hline & & г. Москва & $\begin{array}{l}\text { Национальный исследовательский } \\
\text { университет «МЭИ» } 3\end{array}$ & & & & $1001+$ & & $1001+$ \\
\hline & & г. Москва & $\begin{array}{l}\text { Московский государственный техни- } \\
\text { ческий университет имени Н.Э. Баума- } \\
\text { на (национальный исследовательский } \\
\text { университет) } 3\end{array}$ & 299 & 284 & 282 & $\begin{array}{l}801- \\
1000\end{array}$ & $\begin{array}{l}801- \\
1000\end{array}$ & $\begin{array}{c}401- \\
500\end{array}$ \\
\hline & & г. Москва & $\begin{array}{l}\text { Московский государственный инсти- } \\
\text { тут международных отношений } 4\end{array}$ & 355 & 366 & 348 & & & \\
\hline & & г. Москва & $\begin{array}{l}\text { Российский экономический универси- } \\
\text { тет имени Г. В.Плеханова } 4\end{array}$ & $\begin{array}{l}801- \\
1000\end{array}$ & $\begin{array}{c}751- \\
800\end{array}$ & $\begin{array}{c}751- \\
800\end{array}$ & & & \\
\hline & & г. Москва & $\begin{array}{l}\text { Московский государственный универ- } \\
\text { ситет имени М.В.Ломоносова } 4\end{array}$ & 90 & 84 & 74 & 199 & 189 & 174 \\
\hline & & г. Москва & $\begin{array}{l}\text { Российский технологический универ- } \\
\text { ситет МИРЭА } 4\end{array}$ & & & & $1001+$ & $1001+$ & $1001+$ \\
\hline & & г. Москва & $\begin{array}{l}\text { Российская академия народного хо- } \\
\text { зяйства и государственной службы при } \\
\text { Президенте РФ }\end{array}$ & & & $\begin{array}{l}801- \\
1000\end{array}$ & & & $1001+$ \\
\hline
\end{tabular}




\begin{tabular}{|c|c|c|c|c|c|c|c|c|c|}
\hline \multirow{5}{*}{2} & \multirow{5}{*}{$\begin{array}{c}\text { г. Санкт- } \\
\text { Петербург }\end{array}$} & $\begin{array}{c}\text { г. Санкт- } \\
\text { Петербург }\end{array}$ & $\begin{array}{l}\text { Санкт-Петербургский национальный- } \\
\text { исследовательский университет ин- } \\
\text { формационных технологий, механики } \\
\text { и оптики } 1,3\end{array}$ & $\begin{array}{c}511- \\
520\end{array}$ & 436 & 360 & $\begin{array}{c}501- \\
600\end{array}$ & $\begin{array}{c}401- \\
500\end{array}$ & $\begin{array}{c}501- \\
600\end{array}$ \\
\hline & & $\begin{array}{c}\text { г. Санкт- } \\
\text { Петербург }\end{array}$ & $\begin{array}{l}\text { Санкт-Петербургский государствен- } \\
\text { ный электротехнический университет } \\
\text { «ЛЭИ» } 1\end{array}$ & & & $\begin{array}{c}701- \\
750\end{array}$ & $1001+$ & $1001+$ & $1001+$ \\
\hline & & \begin{tabular}{|c|} 
г. Санкт- \\
Петербург
\end{tabular} & $\begin{array}{l}\text { Санкт-Петербургский политехниче- } \\
\text { ский университет Петра Великого } 1,3\end{array}$ & 404 & 439 & 401 & $\begin{array}{c}601- \\
800\end{array}$ & $\begin{array}{c}501- \\
600\end{array}$ & $\begin{array}{c}301- \\
350\end{array}$ \\
\hline & & \begin{tabular}{|c|} 
г. Санкт- \\
Петербург \\
\end{tabular} & $\begin{array}{l}\text { Санкт-Петербургский горный универ- } \\
\text { ситет } 3\end{array}$ & & & & & $\begin{array}{l}801- \\
1000\end{array}$ & $\begin{array}{c}401- \\
500\end{array}$ \\
\hline & & \begin{tabular}{|c|} 
г. Санкт- \\
Петербург \\
\end{tabular} & $\begin{array}{l}\text { Санкт-Петербургский государствен- } \\
\text { ный университет } 4\end{array}$ & 235 & 234 & 225 & $\begin{array}{c}501- \\
600 \\
\end{array}$ & $\begin{array}{c}601- \\
800 \\
\end{array}$ & $\begin{array}{c}601- \\
800 \\
\end{array}$ \\
\hline \multirow{3}{*}{3} & \multirow{3}{*}{$\begin{array}{l}\text { Томская } \\
\text { область }\end{array}$} & г. Томск & $\begin{array}{l}\text { Национальный исследовательский } \\
\text { Томский политехнический универси- } \\
\text { тет } 1,3\end{array}$ & 373 & 387 & 401 & $\begin{array}{c}501- \\
600\end{array}$ & $\begin{array}{c}601- \\
800\end{array}$ & $\begin{array}{l}801- \\
1000\end{array}$ \\
\hline & & г. Томск & $\begin{array}{l}\text { Национальный исследовательский } \\
\text { Томский государственный универси- } \\
\text { тет } 1,3\end{array}$ & 277 & 268 & 250 & $\begin{array}{c}501- \\
600\end{array}$ & $\begin{array}{c}501- \\
600\end{array}$ & $\begin{array}{c}501- \\
600\end{array}$ \\
\hline & & г. Томск & $\begin{array}{l}\text { Томский государственный универси- } \\
\text { тет систем управления и радиоэлек- } \\
\text { троники } 4 \\
\end{array}$ & & & & & & $1001+$ \\
\hline \multirow{3}{*}{4} & \multirow{3}{*}{$\begin{array}{l}\text { Республи- } \\
\text { ка Татар- } \\
\text { стан }\end{array}$} & г. Казань & $\begin{array}{l}\text { Казанский (Приволжский) федераль- } \\
\text { ный университет 1,2 }\end{array}$ & 439 & 392 & 370 & $\begin{array}{c}601- \\
800\end{array}$ & $\begin{array}{c}601- \\
800\end{array}$ & $\begin{array}{c}601- \\
800\end{array}$ \\
\hline & & г. Казань & $\begin{array}{l}\text { Казанский национальный исследова- } \\
\text { тельский технический университет им. } \\
\text { А.Н. Туполева-КАИ }\end{array}$ & & & & & & $1001+$ \\
\hline & & г. Казань & $\begin{array}{l}\text { Казанский национальный исследова- } \\
\text { тельский технологический универси- } \\
\text { тет } 3\end{array}$ & & & & $1001+$ & $1001+$ & $1001+$ \\
\hline \multirow[t]{2}{*}{5} & \multirow{2}{*}{$\begin{array}{l}\text { Новоси- } \\
\text { бирская } \\
\text { область }\end{array}$} & $\begin{array}{c}\text { г. Новоси- } \\
\text { бирск }\end{array}$ & $\begin{array}{l}\text { Новосибирский национальный } \\
\text { исследовательский государственный } \\
\text { университет } 1,3\end{array}$ & 244 & 231 & 228 & $\begin{array}{c}501- \\
600\end{array}$ & $\begin{array}{c}501- \\
600\end{array}$ & $\begin{array}{c}601- \\
800\end{array}$ \\
\hline & & \begin{tabular}{|c|} 
г. Новоси- \\
бирск
\end{tabular} & $\begin{array}{l}\text { Новосибирский Государственный } \\
\text { Технический Университет } 4\end{array}$ & $\begin{array}{l}801- \\
1000\end{array}$ & $\begin{array}{l}801- \\
1000\end{array}$ & $\begin{array}{l}801- \\
1000\end{array}$ & $\begin{array}{l}801- \\
1000\end{array}$ & $1001+$ & $1001+$ \\
\hline \multirow[b]{2}{*}{6} & \multirow{2}{*}{$\begin{array}{c}\text { Пермская } \\
\text { область }\end{array}$} & г. Пермь & $\begin{array}{l}\text { Пермский государственный исследо- } \\
\text { вательский университет } 3\end{array}$ & & & $\begin{array}{l}801- \\
1000\end{array}$ & $1001+$ & $1001+$ & $1001+$ \\
\hline & & г. Пермь & $\begin{array}{l}\text { Пермский национальный исследова- } \\
\text { тельский политехнический универси- } \\
\text { тет } 3\end{array}$ & & & & 1001 & $1001+$ & $1001+$ \\
\hline \multirow[t]{2}{*}{7} & \multirow{2}{*}{$\begin{array}{l}\text { Самар- } \\
\text { ская } \\
\text { область }\end{array}$} & г. Самара & $\begin{array}{l}\text { Самарский национальный исследо- } \\
\text { вательский университет академика } \\
\text { С.П. Королева } 1,3\end{array}$ & $\begin{array}{c}701- \\
750\end{array}$ & $\begin{array}{c}651- \\
700\end{array}$ & $\begin{array}{c}591- \\
600\end{array}$ & $\begin{array}{l}801- \\
1000\end{array}$ & $1001+$ & $1001+$ \\
\hline & & г. Самара & $\begin{array}{l}\text { Самарский государственный техниче- } \\
\text { ский университет } 4\end{array}$ & & & & & & $1001+$ \\
\hline \multirow{2}{*}{8} & \multirow{2}{*}{\begin{tabular}{c|} 
Респу- \\
блика \\
Башкор- \\
тостан
\end{tabular}} & г. Уфа & $\begin{array}{l}\text { Башкирский государственный универ- } \\
\text { ситет } 4\end{array}$ & & & & & $1001+$ & $1001+$ \\
\hline & & г. Уфа & $\begin{array}{l}\text { Уфимский государственный авиацион- } \\
\text { ный технический университет } 4\end{array}$ & & & & & $1001+$ & $1001+$ \\
\hline 9 & $\begin{array}{c}\text { Алтай- } \\
\text { ский край }\end{array}$ & г. Барнаул & $\begin{array}{l}\text { Алтайский государственный универ- } \\
\text { ситет } 4\end{array}$ & $\begin{array}{c}601- \\
650\end{array}$ & & $\begin{array}{c}571- \\
580\end{array}$ & & & \\
\hline 10 & $\begin{array}{c}\text { Белго- } \\
\text { родская } \\
\text { область }\end{array}$ & $\begin{array}{l}\text { г. Белго- } \\
\text { род }\end{array}$ & $\begin{array}{l}\text { Белгородский государственный наци- } \\
\text { ональный исследовательский универ- } \\
\text { ситет } 3\end{array}$ & & & & $\begin{array}{l}801- \\
1000\end{array}$ & $1001+$ & $1001+$ \\
\hline 11 & $\begin{array}{c}\text { Волго- } \\
\text { градская } \\
\text { область }\end{array}$ & $\begin{array}{l}\text { г. Волго- } \\
\text { град }\end{array}$ & $\begin{array}{l}\text { Волгоградский государственный тех- } \\
\text { нический университет } 4\end{array}$ & & & & $1001+$ & $1001+$ & $\begin{array}{l}801- \\
1000\end{array}$ \\
\hline 12 & $\begin{array}{c}\text { Воро- } \\
\text { нежская } \\
\text { область }\end{array}$ & $\begin{array}{l}\text { г. Воро- } \\
\text { неж }\end{array}$ & $\begin{array}{l}\text { Воронежский государственный уни- } \\
\text { верситет } 4\end{array}$ & $\begin{array}{l}801- \\
1000\end{array}$ & $\begin{array}{l}801- \\
1000\end{array}$ & & $1001+$ & $1001+$ & $1001+$ \\
\hline
\end{tabular}




\begin{tabular}{|c|c|c|c|c|c|c|c|c|c|}
\hline 13 & $\begin{array}{l}\text { Сверд- } \\
\text { ловская } \\
\text { область }\end{array}$ & $\begin{array}{l}\text { г. Екате- } \\
\text { ринбург }\end{array}$ & $\begin{array}{l}\text { Уральский федеральный университет } \\
\text { имени первого президента Рос- } \\
\text { сии Б. Н.Ельцина } 1,2\end{array}$ & 412 & 364 & 331 & $1001+$ & $1001+$ & $1001+$ \\
\hline 14 & $\begin{array}{l}\text { Иркутская } \\
\text { область }\end{array}$ & г. Иркутск & $\begin{array}{l}\text { Иркутский государственный универ- } \\
\text { ситет } 4\end{array}$ & & & & & & $1001+$ \\
\hline 15 & \begin{tabular}{|c|} 
Калинин- \\
градская \\
область \\
\end{tabular} & $\begin{array}{l}\text { г. Кали- } \\
\text { нинград }\end{array}$ & $\begin{array}{l}\text { Балтийский федеральный университет } \\
\text { имени Иммануила Канта } 1,2\end{array}$ & & & & & & $1001+$ \\
\hline 16 & $\begin{array}{l}\text { Краснояр- } \\
\text { ский край }\end{array}$ & $\begin{array}{c}\text { г. Красно- } \\
\text { ярск }\end{array}$ & $\begin{array}{l}\text { Сибирский федеральный университет } \\
1,2\end{array}$ & $\begin{array}{l}801- \\
1000\end{array}$ & & & $1001+$ & $1001+$ & $1001+$ \\
\hline 17 & $\begin{array}{l}\text { Нижего- } \\
\text { родская } \\
\text { область }\end{array}$ & $\begin{array}{l}\text { г. Н.Нов- } \\
\text { город }\end{array}$ & $\begin{array}{l}\text { Национальный исследовательский } \\
\text { Нижегородский государственный уни- } \\
\text { верситет им. И. И. Лобачевского } 1,3\end{array}$ & $\begin{array}{c}601- \\
650\end{array}$ & $\begin{array}{c}601- \\
650\end{array}$ & $\begin{array}{c}601- \\
650\end{array}$ & $1001+$ & $1001+$ & $1001+$ \\
\hline 18 & $\begin{array}{l}\text { Ростов- } \\
\text { ская } \\
\text { область }\end{array}$ & $\begin{array}{l}\text { г. Ростов- } \\
\text { на-Дону }\end{array}$ & Южный федеральный университет 2 & $\begin{array}{c}531- \\
540\end{array}$ & $\begin{array}{c}541- \\
550\end{array}$ & $\begin{array}{c}591- \\
600\end{array}$ & $1001+$ & $1001+$ & $1001+$ \\
\hline 19 & $\begin{array}{c}\text { Сара- } \\
\text { товская } \\
\text { область }\end{array}$ & г. Саратов & $\begin{array}{l}\text { Национальный исследовательский Са- } \\
\text { ратовский государственный универси- } \\
\text { тет имени Н.Г. Чернышевского } 3\end{array}$ & $\begin{array}{c}501- \\
510\end{array}$ & $\begin{array}{c}521- \\
530\end{array}$ & $\begin{array}{c}521- \\
530\end{array}$ & $1001+$ & $1001+$ & $1001+$ \\
\hline 20 & $\begin{array}{c}\text { Челя- } \\
\text { бинская } \\
\text { область }\end{array}$ & $\begin{array}{l}\text { г. Челя- } \\
\text { бинск }\end{array}$ & $\begin{array}{l}\text { Южно-Уральский государственный } \\
\text { университет (национальный исследо- } \\
\text { вательский университет) } 1,3\end{array}$ & $\begin{array}{l}801- \\
1000\end{array}$ & $\begin{array}{l}801- \\
1000\end{array}$ & $\begin{array}{l}801- \\
1000\end{array}$ & & $1001+$ & $1001+$ \\
\hline 21 & $\begin{array}{c}\text { Республи- } \\
\text { ка Саха }\end{array}$ & г. Якутск & $\begin{array}{l}\text { Северо-Восточный федеральный уни- } \\
\text { верситет имени М. К. Аммосова } 2\end{array}$ & & & & & & $1001+$ \\
\hline 22 & $\begin{array}{c}\text { Примор- } \\
\text { ский край }\end{array}$ & $\begin{array}{l}\text { г. Влади- } \\
\text { восток }\end{array}$ & $\begin{array}{l}\text { Дальневосточный федеральный уни- } \\
\text { верситет } 1,2\end{array}$ & $\begin{array}{c}541- \\
550\end{array}$ & $\begin{array}{c}531- \\
540\end{array}$ & 493 & $1001+$ & $1001+$ & $1001+$ \\
\hline 23 & $\begin{array}{l}\text { Омская } \\
\text { область }\end{array}$ & г.Омск & $\begin{array}{l}\text { Омский государственный технический } \\
\text { университет } 4\end{array}$ & & & & & & $1001+$ \\
\hline
\end{tabular}

1 - Глобальные университеты, 2 - Федеральные университеты, 3 - Национальные исследовательские университеты, 4 Ведущие российские университеты не входящие в предыдущие списки, но входящие в один из глобальных рейтингов (QS, THE).

Так как рейтинги QS и THE слабо согласуются между собой на всей выборке университетов, что видно из таблицы 1 , то мы будем рассчитывать $R_{i}$ отдельно для каждого рейтинга, как средние арифметические значения по всем университетам, входящих в $i-$ ый регион. В случае интервальных оценок рейтингов университетов, мы будем брать середину этих интервалов, а для ранга 1001+ рейтинга ТНЕ будем для простоты брать ранг 1001. Например, чтобы посчитать $R_{2}$ (Санкт-Петербург) для рейтинга QS нужно просуммировать все ранги санктпетербургских университетов и разделить на их количество: $R_{2}=(515+436+360+725+404+439+401+235+$ $234+225) / 10=397.4$.

На основе вектора $\left(n_{i}, R_{i}\right)$ в работе [2] были предложены три варианта расчета интегрального показателя региональной университетской конкурентоспособности, при этом расчет первых двух вариантов ведется мультипликативным способом, а третьего - аддитивным. Ниже приведем соответствующие три формулы для расчета этого показателя:

$$
\begin{aligned}
& I_{1 i}=\left(\frac{n_{i}}{n_{\max }}\right)\left(1-\frac{R_{i}}{R_{\max }}\right) \\
& I_{2 i}=\sqrt{\left(\frac{n_{i}}{n_{\max }}\right)\left(1-\frac{R_{i}}{R_{\max }}\right)} \\
& I_{3 i}=\frac{n_{i}}{n_{\max }}+\left(1-\frac{R_{i}}{R_{\max }}\right)
\end{aligned}
$$

\section{Результаты и обсуждения}

Расчеты по формулам (1-3) для рейтингов QS и THE, проделанные на основе таблицы 1 , представлены в таблице 2. Для регионов с отсутствующими рейтингами университетов, расчеты, естественно, не проводились. Для рейтингов QS и THE nmax $=17$, для рейтинга QS $R_{\max }=900$, а для ТНЕ $R_{\max }=1001$. 
Таблица 2. Расчеты интегральных показателей региональной университетской конкурентоспособности, проделанные на основе формул (1-3) с использованием таблицы 1

\begin{tabular}{|c|c|c|c|c|c|c|c|c|c|c|}
\hline № & Регион & $\begin{array}{c}\text { Коли- } \\
\text { чество } \\
\text { универ- } \\
\text { ситетов } \\
\text { (n) } \\
\end{array}$ & $\begin{array}{c}\text { Сред- } \\
\text { ний } \\
\text { рейтинг } \\
R_{i}(\mathrm{QS})\end{array}$ & $\begin{array}{l}I_{1 i} \\
(\mathrm{QS})\end{array}$ & $\begin{array}{c}I_{2 i} \\
(\mathrm{QS})\end{array}$ & $\begin{array}{l}I_{3 i} \\
(\mathrm{QS})\end{array}$ & $\begin{array}{c}\text { Сред- } \\
\text { ний } \\
\text { рейтинг } \\
R_{i} \text { (ТНЕ) }\end{array}$ & $\begin{array}{c}I_{1 i} \\
\text { (THE) }\end{array}$ & $\begin{array}{c}I_{2 i} \\
(\mathrm{THE})\end{array}$ & $\begin{array}{c}I_{3 i} \\
(\mathrm{THE})\end{array}$ \\
\hline 1 & г. Москва & 17 & 422.70 & 0.5303 & 0.7282 & 1.5303 & 728.30 & 0.2724 & 0.5219 & 1.2724 \\
\hline 2 & г. Санкт-Петербург & 5 & 397.40 & 0.1642 & 0.4053 & 0.8526 & 673.43 & 0.0962 & 0.3102 & 0.6214 \\
\hline 3 & Томская область & 3 & 326.00 & 0.1125 & 0.3355 & 0.8142 & 685.86 & 0.0556 & 0.2357 & 0.4913 \\
\hline 4 & Республика Татарстан & 3 & 400.33 & 0.0980 & 0.3130 & 0.7317 & 872.00 & 0.0227 & 0.1508 & 0.3053 \\
\hline 5 & Новосибирская область & 2 & 567.17 & 0.0435 & 0.2086 & 0.4875 & 783.67 & 0.0255 & 0.1598 & 0.3348 \\
\hline 6 & Пермская область & 2 & 900.00 & 0.0000 & 0.0000 & 0.1176 & 1001.00 & 0.0000 & 0.0000 & 0.1176 \\
\hline 7 & Самарская область & 2 & 665.00 & 0.0307 & 0.1753 & 0.3788 & 975.75 & 0.0030 & 0.0545 & 0.1429 \\
\hline 8 & Республика Башкортостан & 2 & & & & & 1001.00 & 0.0000 & 0.0000 & 0.1176 \\
\hline 9 & Алтайский край & 1 & 600.00 & 0.0196 & 0.1400 & 0.3922 & & & & \\
\hline 10 & Белгородская область & 1 & & & & & 967.33 & 0.0020 & 0.0445 & 0.0925 \\
\hline 11 & Волгоградская область & 1 & & & & & 967.33 & 0.0020 & 0.0445 & 0.0925 \\
\hline 12 & Воронежская область & 1 & 900.00 & 0.0000 & 0.0000 & 0.0588 & 1001.00 & 0.0000 & 0.0000 & 0.0588 \\
\hline 13 & Свердловская область & 1 & 369.00 & 0.0347 & 0.1863 & 0.6488 & 1001.00 & 0.0000 & 0.0000 & 0.0588 \\
\hline 14 & Иркутская область & 1 & & & & & 1001.00 & 0.0000 & 0.0000 & 0.0588 \\
\hline 15 & Калининградская область & 1 & & & & & 1001.00 & 0.0000 & 0.0000 & 0.0588 \\
\hline 16 & Красноярский край & 1 & 900.00 & 0.0000 & 0.0000 & 0.0588 & 1001.00 & 0.0000 & 0.0000 & 0.0588 \\
\hline 17 & Нижегородская область & 1 & 625.00 & 0.0180 & 0.1341 & 0.3644 & 1001.00 & 0.0000 & 0.0000 & 0.0588 \\
\hline 18 & Ростовская область & 1 & 558.33 & 0.0223 & 0.1494 & 0.4385 & 1001.00 & 0.0000 & 0.0000 & 0.0588 \\
\hline 19 & Саратовская область & 1 & 518.33 & 0.0249 & 0.1579 & 0.4829 & 1001.00 & 0.0000 & 0.0000 & 0.0588 \\
\hline 20 & Челябинская область & 1 & 900.00 & 0.0000 & 0.0000 & 0.0588 & 1001.00 & 0.0000 & 0.0000 & 0.0588 \\
\hline 21 & Республика Саха & 1 & & & & & 1001.00 & 0.0000 & 0.0000 & 0.0588 \\
\hline 22 & Приморский край & 1 & 524.33 & 0.0246 & 0.1567 & 0.4762 & 1001.00 & 0.0000 & 0.0000 & 0.0588 \\
\hline 23 & Омская область & 1 & & & & & 1001.00 & 0.0000 & 0.0000 & 0.0588 \\
\hline
\end{tabular}

Из таблицы 2 следует, что по всем шести интегральным показателям региональной университетской конкурентоспособности лидируют первые пять регионов (Москва, Санкт-Петербург, Томская область, Республика Татарстан, Новосибирская область). Значения этих показателей для Москвы превышают аналогичные значения для Санкт-Петербурга в интервале от 1.68 до 3.23 со средним значением 2.23 .

Кросскорреляционная матрица для шести интегральных показателей региональной университетской конкурентоспособности, рассчитанная по пятнадцати значениям этих показате- лей в таблице 2, приведена в таблице 3 . Высокие значения коэффициента корреляции Пирсона в этой матрице говорят о том, что в относительном плане для практических расчетов можно пользоваться любой из формул (1-3).

\section{ЗАКЛЮЧЕНИЕ}

В работе идентифицированы российские университеты, которые входили, по крайней мере, в один из рейтингов QS или THE за последние три года. Таких университетов оказалось 51. Эти университеты были распределены по двадцати трем российским регионам. Для каждого

Таблица 3. Кросскорреляционная матрица для интегральных показателей региональной университетской конкурентоспособности

\begin{tabular}{|c|c|c|c|c|c|c|}
\hline & $I_{1 i}(\mathrm{QS})$ & $I_{2 i}(\mathrm{QS})$ & $I_{3 i}(\mathrm{QS})$ & $I_{1 i}(\mathrm{THE})$ & $I_{2 i}(\mathrm{THE})$ & $I_{3 i}(\mathrm{THE})$ \\
\hline$I_{1 i}(\mathrm{QS})$ & 1 & & & & & \\
\hline$I_{2 i}(\mathrm{QS})$ & 0.92590727 & 1 & & & & \\
\hline$I_{3 i}(\mathrm{QS})$ & 0.893168618 & 0.986343203 & 1 & & & \\
\hline$I_{1 i}(T H E)$ & 0.990848868 & 0.89963396 & 0.856034224 & 1 & & \\
\hline$I_{2 i}(T H E)$ & 0.925854928 & 0.933762507 & 0.88060062 & 0.93964781 & 1 & \\
\hline$I_{3 i}(T H E)$ & 0.96549901 & 0.926741085 & 0.877472281 & 0.977744124 & 0.988178159 & 1 \\
\hline
\end{tabular}


региона было подсчитано количество, входящих в него университетов, и их усредненное позиционирование в рассматриваемых двух рейтингах отдельно.

С использованием методологии расчета интегрального показателя региональной университетской конкурентоспособности, предложенной в работе [2], были рассчитаны значения этих показателей в трех вариантах для каждого из рейтингов. В результате были выделены пять лидирующих регионов или центров университетского превосходства - Москва, Санкт-Петербург,
Томская область, Республика Татарстан и Новосибирская область.

Получена хорошая парная корреляция между всеми значениями шести интегральных показателей. Предложенная методология может быть использована для пространственного анализа университетской конкурентоспособности регионов любых стран, а также любой совокупности стран мира. В последнем случае, ее удобно использовать для рейтинга Webometrics, в который входит достаточно много университетов от каждой страны.

\section{Библиографический список}

1. Московкин В. М., Чжан Хэ, Садовски М.В. Какие российские университеты имеют шансы войти в 2020 г. в ТОР-100 трёх ведущих мировых рейтингов? //Экономика науки. - 2019. - Том 5, № 2.- С. 143-156.

2. Московкин В. М., Лю Явэй. К оценке региональной университетской конкурентоспособности // Научный результат. Экономические исследования.-2018. - Том 4, № 1.- С. 35-53. 